\title{
Oral Sub Mucous Fibrosis: Exploring Therapeutic Strategies Using -anti TGF $\beta$ Drugs
}

\author{
Sheshaprasad R ${ }^{1}$, Anuradha Pai ${ }^{2}$
}

${ }^{1}$ Senior Lecturer, Department of Oral Medicine and Radiology, The Oxford Dental College and Hospital, Bangalore. ${ }^{2}$ Head of the Department, Department of Oral Medicine and Radiology, The Oxford Dental College and Hospital, Bangalore.

\begin{abstract}
Objective: Oral submucous fibrosis (OSMF) is a chronic irreversible potentially malignant condition causing morbidity. Transforming Growth Factor beta (TGF- $\beta 1$ ) plays the central role in its development. Hence early intervention is the key to limit the progress of the disease. The aim of this paper was to review the effective therapeutic agents available to neutralize the pathological effect of TGF- $\beta 1$ in OSMF. Methods: An electronic search was conducted and we reviewed the records of the https://clinicaltrials.gov/, the registry of clinical trials that have been conducted internationally and in the United States in order to look for drugs associated with different types of fibrotic disorder. The studies related to pulmonary fibrosis were also included. We performed another search in the PubMed database and chose the successfully tested drugs as the result of our previous search and used the keywords "Name of the selected drug" "TGF" "Fibrosis." Results: A total of 89 studies were listed in the search and finally, 9 studies were considered for the analysis. The search results indicated the potential benefit of two drugs namely nintedanib and pirfenidone. It was noted that nintedanib reversed TGF- $\beta 1$-induced EMT in non-small cell lung cancer cells and pirfenidone treatment inhibited TGF- $\beta 1$-induced up-regulation of phosphorylation of ERK1/2, p38 and Jun amino-terminal kinases (JNK) in a renal fibrosis rat model. Conclusion: It was concluded that pirfenidone and nintedanib were found to have a promising role in the treatment of pulmonary fibrosis also linked to the pathological effect of TGF- $\beta$ pathway. Therefore, we put forward the suggestion of designing preclinical studies, as well as clinical trials to test the effectiveness of these drugs in treating oral submucous fibrosis.
\end{abstract}

Keywords: OSMF-potentially malignant condition- TGF- $\beta 1$ - pirfenidone

Asian Pac J Cancer Care, 3 (2), 21-27

\section{Introduction}

Fibrosis includes a wide range of diseases including systemic sclerosis (SSc), idiopathic pulmonary fibrosis (IPF), liver and renal fibrosis, and oral submucous fibrosis (OSMF) [1-11]. It is a chronic disease, which affects a large number of individuals posing a challenge to the healthcare professionals and economic burden to the patients. It has been estimated that the fibrotic diseases are responsible for approximately $45 \%$ of mortalities in the Western countries. However, developing countries have a higher mortality rate [10-12].

In renal fibrosis, differentiation of myofibroblasts and collagen synthesis is stimulated by cytokines and growth factors, which are secreted from the adjacent tubular epithelial cells, endothelial cells, or from fibroblasts.
Submission Date: 02/11/2018 Acceptance Date: 05/01/2018

The most crucial role is played by transforming growth factor beta-1 (TGF- $\beta 1$ ) [13]. IPF is a progressive lung disease, which is characterized by an injury of the alveolar epithelial cell, activated fibroblasts and myofibroblasts proliferation, and extracellular matrix (ECM) accumulation. TGF- $\beta 1$ is associated with fibroblast proliferation and accumulation in IPF [14]. Systemic sclerosis is characterized by fibrosis of various organs including the skin, kidney, heart, lungs, and digestive system. Damage of the endothelial cells takes place and fibroblasts are activated by an autoantibody-mediated mechanism. The TGF- $\beta 1$ pathway is a critical signaling pathway in the development of systemic sclerosis [15]. In liver fibrosis, hepatic stellate cells get activated and are transformed into myofibroblasts, which produce ECM leading to fibrosis. In OSMF, oral epithelial cells secrete

Corresponding Author:

Dr. Sheshaprasad R

Department of Senior Lecturer, Department of Oral Medicine and Radiology, The Oxford Dental College and Hospital,Bangalore.

Email: drsheshaprasad@gmail.com 
TGF- $\beta 1$ [16], which stimulates cytokine expression by the connective tissue leading to fibroelastic changes in lamina propria, connective tissue, blood vessels, and degenerative changes in the muscles.

Although fibrotic disorders arise in different tissues and various risk factors (Table 1) are associated with the disease development and progression, there are certain common features, which are observed among the affected tissues in fibrosis. It has been reported that transforming growth factor pathway, vascular endothelial growth factor pathway, PDGF pathway, and fibroblast growth factor pathway are involved in the pathogenesis of fibrosis [17]. In the fibrotic tissue, trans-differentiation of epithelial cells to myofibroblasts occurs by a process known as the epithelial-mesenchymal transition (EMT) [18-19]. Additionally, there is also an increase in production of collagens, secretion of $\alpha$-smooth muscle actin ( $\alpha$-SMA), reduction of the extracellular degradative enzyme, excessive accumulation of ECM with components such as hyaluronic acid, fibronectin, proteoglycans, and collagens that lead to the formation of permanent fibrotic scar [10, 19-23]. The excessive accumulation of ECM proteins is caused due to high production of tissue inhibitors of metalloproteinases (TIMP) by myofibroblasts, which inhibit the action of various matrix metalloproteinases (MMPs) [24-25].

TGF- $\beta 1$ plays the central role in fibrosis. TGF- $\beta 1$, the most profibrogenic growth factor, causes transcriptional activation of various genes such as COMP, CTGF, PAI, NOX4, and numerous other genes involved in the fibrotic process [25]. Several studies have also demonstrated that TGF- $\beta 1$ is involved in the generation of myofibroblasts through EMT [26-32]. TGF- $\beta 1$ also promotes wound closure and scarring [33-35] and has been known to induce excess matrix synthesis when injected subcutaneously in mice or into metal chambers implanted in the back of rats [34-36].

Up-regulation of TGF- $\beta 1$, down-regulation of bone morphogenic protein (BMP) and remodeling of ECM are characteristic features of OSMF, which are characterized by rigidity of the mucous along with fibroelastic changes of the lamina propria [37-41]. The disease affects the oral cavity, pharynx, and the upper one-third part of the esophagus and causes great difficulty in opening the mouth and eating [41-43]. Areca nut chewing is considered as the most probable etiological factor in OSMF [40-44, 45]. The alkaloid and polyphenol components of areca nut were found to be the inducer and activator of TGF- $\beta 1$ in epithelial cells [40]. Exposure to areca nut and stimulation of the TGF- $\beta 1$ pathway are responsible for overproduction of collagen and decrease in degradation of collagen in OSMF [46-47]. TGF- $\beta 1$ induces transcription of COL1A1 procollagen gene $[16,48-50]$, increases activities of procollagen proteinases [46] and promotes the expression of lysyl oxidase (LOX), an enzyme essential for transforming collagen fibers into stable mature fibrillar form [51-52]. It has been shown in immunohistochemical experiments that there is intense TGF- $\beta 1$ staining of the epithelium, fibroblast, macrophages, and inflammatory cells in early
OSMF [16-47]. Furthermore, activated TGF- $\beta 1$ induces myofibroblast transdifferentiation in OSMF [47-53]. Therefore, the TGF- $\beta 1$ function is indispensable for the pathogenesis of oral submucosal fibrosis.

Submucous fibrosis is predominantly found in Indian population and occasionally in the Taiwanese population [54]. There has been a tremendous rise in the incidence of submucous fibrosis in the recent years. In 2002, in the Indian subcontinent alone, 5 million people were affected by the disease [55] [54]. It has been reported that in the Indian states of Bihar, Madhya Pradesh, Gujarat, and Maharashtra, the younger generation is getting addicted to areca nut products [46-54].

The percentage of OSMF among patients attending orthodontics and pediatric dentistry (OPD) in Jaipur, Rajasthan, India in 2012 was found to be $3.39 \%$ [1] [54] and in a 17-year, long-term, follow-up study, the annual malignant transformation rate was found to be approximately $0.5-7.6 \%$ [54-56]. Although there are several drug therapies, surgical therapy, and physiotherapy to manage the symptoms of the disease and to alleviate the symptoms of OSMF, there is no effective treatment for this disorder [57] [58]. In this review paper, we aim to offer suggestions to perform clinical trials on drugs based on molecular pathways of OSMF, mainly the TGF- $\beta 1$ pathway. Since TGF- $\beta 1$ is a common pathway involved in fibrotic diseases, the central idea of this review article is to suggest antifibrotic drugs, which act on the TGF- $\beta 1$ pathway that has already been clinically tested in other fibrotic diseases.

\section{Materials and Methods}

We reviewed the records of the https://clinicaltrials. gov/, the registry of clinical trials that have been conducted internationally and in the United States. We used the advanced search option of the registry, and wrote "FIBROSIS" in the text box provided for "SEARCH TERMS", selected "CLOSED STUDIES" in the drop-down provided for "RECRUITMENT", STUDIES WITH RESULT" in the dropdown provided for "STUDY RESULT", and selected "INTERVENTIONAL STUDIES" for the dropdown provided for "STUDY TYPE" and checked "PHASE 3" in the "PHASE" category. Remaining text boxes were kept in the default mode.

By applying the set criteria in searching the clinical trial registry database, we obtained 89 hits. Out of these 89 hits, we screened the downloaded XML file for entries on pulmonary fibrosis. In the process, we excluded 75 entries, as the studies were not related to pulmonary fibrosis. In the next step, we removed the entries, which did not have associated publications and those entries that were redundant in nature. There were two entries, which were redundant in nature and three entries that did not have publications associated with them. Nine entries were considered for further analysis.

After performing the search in the United States government website on clinical trials data, we performed another search in the PubMed database. We chose the 
successfully tested drugs as the result of our previous search and used the keywords "Name of the selected drug", "TGF" and Fibrosis."

\section{Results}

In the list of studies that we obtained, (Table 2) pirfenidone and nintedanib were the two drugs, which were found to improve conditions associated with IPF; and cyclophosphamide was found to be effective in the treatment of scleroderma interstitial lung disease. On the other hand, there were some drugs in our list, which showed no promise in improving the diseased condition in idiopathic pulmonary disease. Such drugs included sildenafil, which has shown no benefit in the treatment of idiopathic pulmonary disease; warfarin that was associated with increased risk of mortality in idiopathic pulmonary disease population; bosentan that showed no effect when compared to placebo; and ambrisentan, acetylcysteine, combination of prednisone, azathioprine, and $\mathrm{N}$-acetylcysteine that were associated with increased risk of idiopathic pulmonary disease progression and hospitalization.

By a study of the articles we retrieved through our literature search in PubMed, we found out that cyclophosphamide did not inhibit TGF- $\beta 1$-induced signaling, as assessed by luciferase reporter gene expression in lung fibroblast model [59], nintedanib reversed TGF- $\beta 1$-induced EMT in non-small cell lung cancer cells [60], pirfenidone treatment inhibited TGF$\beta 1$-induced upregulation of phosphorylation of ERK1/2, p38 and Jun amino-terminal kinases (JNK) in a renal fibrosis rat model [61].

\section{Discussion}

OSMF is a debilitating disease of the oral cavity. It is one of the most poorly understood oral diseases and no single drug has provided complete relief to the patient [62]. Corticosteroids are immunosuppressive agents, which are commonly used to treat the disease but are not effective in reversing the abnormal deposition of fibrotic tissues. Proteolytic enzymes such as hyaluronidase, collagenase, and chymotrypsin are also used to treat the disease. Hyaluronidase breaks down hyaluronic acid and reduces collagen formation. Vitamins, antioxidants, minerals, and lycopene have shown improvement in the disease condition. Antifibrotic drugs such as interferon gamma; however, improved mouth opening and reduced burning sensation; it has definite adverse effects. However, surgical treatment treats severe trismus by incising the fibrous bands; it may lead to further fibrosis [62]. Lack of good quality clinical trials of drugs used in the treatment of OSMF and lack of evidence for the use of specific intervention has made the management of OSMF difficult [63]. Therefore, there is a need for alternative therapies that can be used to effectively manage the disease and prevent its malignant transformation.

By performing a systematic search of the clinical trial database and PubMed literature, we obtained only two

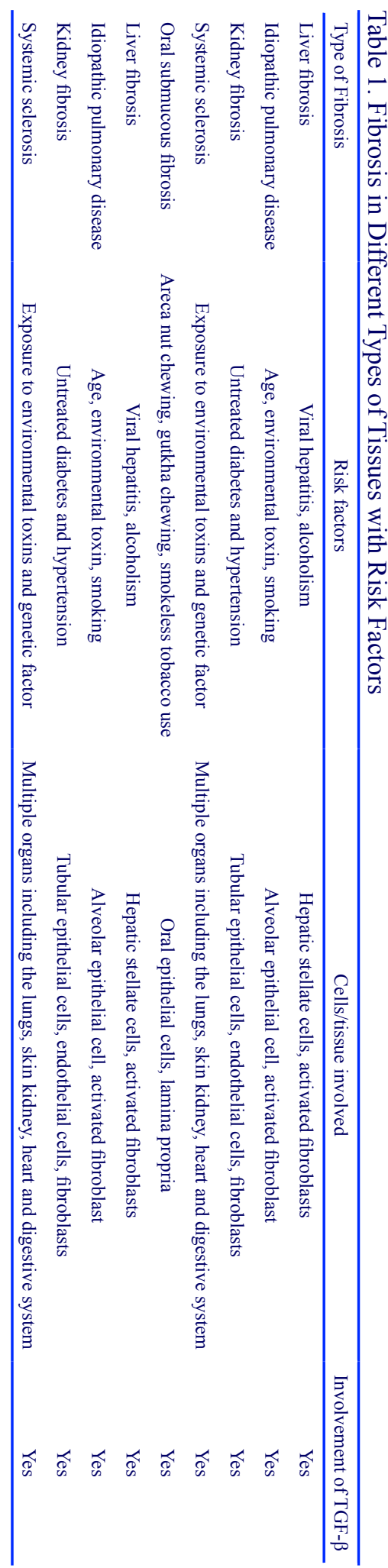

drugs namely pirfenidone and nintedanib, which have shown promise in treating fibrotic disorders of the lung.

Gadekar [64] studied several pyridone derivatives and reported that 5-methyl-1-phenyl-2-(1H)-pyridone (which was later named pirfenidone) had analgesic, antipyretic, and anti-inflammatory activities. Margolin [65] reported that the drug can act as an antifibrotic agent. Later in 2007 , patent rights of the drug were purchased by InterMune Inc. for the United States and Europe from Marnac. In Japan, pirfenidone is sold by Shionogi as Pirespa ${ }^{\circledR}$ and in India, 


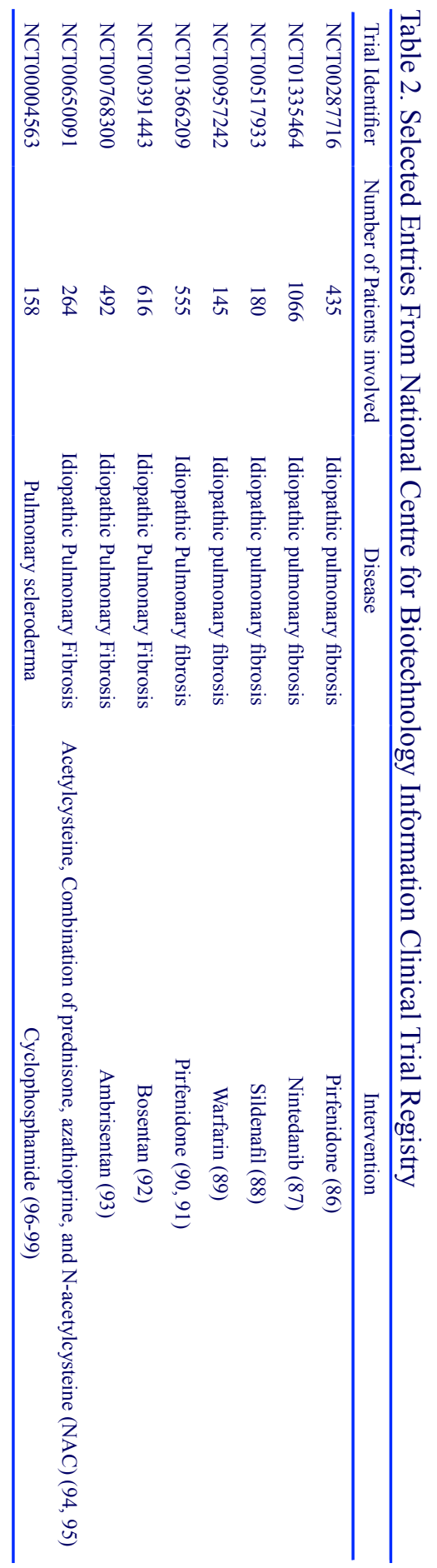

Cipla began the sale of the drug in October 2010.

In human myometrial and leiomyoma cells, pirfenidone inhibits cell proliferation, by reducing the rate of deoxyribonucleic acid (DNA) synthesis, and also decreases levels of messenger RNAs (mRNAs) encoding collagen I and collagen III [66]. In human retinal pigment epithelial cells, a TGF- $\beta 1$-induced increase in fibronectin synthesis is inhibited by Pirfenidone [67]. In the patent application, Margolin reported that pirfenidone inhibited, TGF- $\beta 1$-induced collagen production from fibroblasts [65] and in a hamster model, pirfenidone decreased collagen gene expression [68]. Moreover, pirfenidone has been shown to attenuate liver [69] and cardiac fibrosis
[70]. Its effect in treating OSMF has not yet been tested in preclinical and human clinical trials. In this review, we suggest pirfenidone as a potential candidate drug in the treatment of OSMF.

Pirfenidone may reduce OSMF by the following mechanisms:

1) By decreasing the levels of mRNA encoding type I and III collagen and also inhibiting TGF- $\beta 1$-induced collagen production from fibroblasts [71].

2) By inhibiting tissue inhibitor of metalloproteinases- 1 (TIMP1), which is upregulated in OSMF $(72,73)$.

3) By suppressing proinflammatory cytokines TNF- $\alpha$, which is upregulated in OSMF [74-75].

4) By down-regulating fibroblast growth factor (b-FGF), which interacts synergistically with other growth factors enhancing the extracellular matrix deposition in OSMF [76-77].

5) By reducing the level of plasminogen activator inhibitor-1 (PAI-1), which is upregulated by TGF- $\beta 1$ in OSMF [78].

Originally, nintedanib was developed as a cancer drug and was used as a second-line therapy for lung cancer of the adenocarcinoma subtype. Nintedanib, also known as BIBF 1120 , is an orally available tyrosine kinase inhibitor, which inhibits PDGF receptor- $\alpha$ and $-\beta$, vascular endothelial growth factor receptor- $1,-2$ as well as fibroblast growth factor receptor-1, -2 , and -3 [79]. Most importantly, nintedanib has shown inhibition of TGF- $\beta 1$ profibrotic effect in human lung fibroblast [80] and also the improvement in bleomycin-induced pulmonary fibrosis in rodents [81]. Based on its mode of action, we suggest the human clinical trial of this drug in the treatment of OSMF.

Moreover, we suggest that nintedanib may reduce OSMF through the following mechanism:

1) By directly preventing phosphorylation of TGF- $\beta 1$ receptor and reducing excessive ECM production which is a hallmark of OSMF [82].

2) By targeting PDGF receptor- $\alpha$ and- $\beta$ and thus reducing the level of PDGF, which is up-regulated in OSMF [38].

3) By targeting fibroblast growth factor receptor- $1,-2$, and -3 and thereby reducing the level of fibroblast growth factor, which may be a potential biomarker for malignant transformation of OSMF [83].

In two clinical trial programs namely TOMORROW trial which was an international phase II trial and two international phase III trials called as INPULSIS trial study conducted for Idiopathic pulmonary fibrosis (IPF) were treated with $150 \mathrm{mg}$ of nintedanib $150 \mathrm{mg}$ twice daily. It was noted that the reduction in mortality all-cause and those related to respiratory causes were decreased by $30 \%$ against the placebo [84].

According to another study, the dosage recommended for pirfenidone is $801 \mathrm{mg}$ three times per day with a two week titration period. The study recommends that the dose modifications are flexible and keeping the safety of the patient can be optimized for patients based on the observable Adverse Events (AE) [85]. 
In conclusion, considering the beneficial effect of pirfenidone and nintedanib in pulmonary fibrosis treatment, their role in reducing TGF- $\beta 1$-induced profibrotic effects and down-regulating various receptors, cytokines and proinflammatory molecules involved in the pathogenesis of OSMF, designing preclinical and clinical trials to test the effectiveness of these drugs in treating OSMF is suggested.

\section{Funding resource}

This research did not receive any specific grant from funding agencies in the public, commercial, or not-forprofit sectors.

\section{References}

1. Cox SC, Walker DM. Oral submucous fibrosis. A review. Australian dental journal. 1996;41(5):294-9.

2. Schnaper HW KJ. Renal fibrosis. Frontiers in bioscience :. a journal and virtual library $2003 ; ; 8:: \mathrm{e} 68-86$.

3. Denton CP BC. Scleroderma--clinical and pathological advances. Best practice \& research Clinical rheumatology. 2004;;18((3):):271-90.

4. Bataller R, Brenner DA. Liver fibrosis. The Journal of clinical investigation. 2005;115(2):209-18.

5. Mendoza FA, Artlett CM, Sandorfi N, Latinis K, PieraVelazquez S, Jimenez SA. Description of 12 cases of nephrogenic fibrosing dermopathy and review of the literature. Seminars in arthritis and rheumatism. 2006;35(4):238-49.

6. PW. N. Idiopathic pulmonary fibrosis: natural history and prognosis. Clinics in chest medicine 2006;;27((1 Suppl 1):):S11-6, v.

7. Varga J, Abraham D. Systemic sclerosis: a prototypic multisystem fibrotic disorder. The Journal of clinical investigation. 2007;117(3):557-67.

8. White JM, Creamer D, du Vivier AW, Pagliuca A, Ho AY, Devereux S, et al. Sclerodermatous graft-versus-host disease: clinical spectrum and therapeutic challenges. The British journal of dermatology. 2007;156(5):1032-8.

9. Cowper SE. Nephrogenic systemic fibrosis: an overview. Journal of the American College of Radiology : JACR. 2008;5(1):23-8.

10. Rosenbloom J, Mendoza FA, Jimenez SA. Strategies for anti-fibrotic therapies. Biochimica et biophysica acta. 2013;1832(7):1088-103.

11. Patil S MS. Proposed new grading of oral submucous fibrosis based on cheek flexibility. Journal of clinical and experimental dentistry. 2014;;6((3):):e255-8.

12. Wynn TA. Cellular and molecular mechanisms of fibrosis. The Journal of pathology. 2008;214(2):199-210.

13. Meng XM, Tang PM, Li J, Lan HY. TGF-beta/Smad signaling in renal fibrosis. Frontiers in physiology. 2015;6:82.

14. Lepparanta O SC, Salmenkivi K, Kinnula VL, Keski-Oja J, Myllarniemi M, et al. . Regulation of TGF-beta storage and activation in the human idiopathic pulmonary fibrosis lung. . Cell and tissue research. 2012;;348((3):):491-503.

15. Varga J PB. Transforming growth factor beta as a therapeutic target in systemic sclerosis. . Nature reviews Rheumatology 2009;;5((4):):200-6.

16. Kale AD MD, Shukla D. . Expression of transforming growth factor beta and its correlation with lipodystrophy in oral submucous fibrosis: an immunohistochemical study. Medicina oral, patologia oral y cirugia bucal. 2013;;18((1):):e12-8.

17. Wollin L WE, Pautsch A, Schnapp G, Hostettler KE,
Stowasser S, et al. . Mode of action of nintedanib in the treatment of idiopathic pulmonary fibrosis. The European Respiratory Journal 2015;;45((5):):1434-45.

18. Quan TE, Cowper SE, Bucala R. The role of circulating fibrocytes in fibrosis. Current rheumatology reports. 2006;8(2):145-50.

19. Wynn TA. Common and unique mechanisms regulate fibrosis in various fibroproliferative diseases. The Journal of clinical investigation. 2007;117(3):524-9.

20. Desmouliere A GG. Myofibroblast differentiation during fibrosis. Experimental nephrology. . 1995;;3((2):):134-9.

21. Abraham DJ EB, Rajkumar V, Krieg T. . New developments in fibroblast and myofibroblast biology: implications for fibrosis and scleroderma. Current rheumatology reports. . 2007;;9((2):):136-43.

22. Krieg T AD, Lafyatis R. . Fibrosis in connective tissue disease: the role of the myofibroblast and fibroblast-epithelial cell interactions. Arthritis research \& therapy. 2007;;9 (Suppl 2:):S4.

23. McAnulty RJ. Fibroblasts and myofibroblasts: their source, function and role in disease. The international journal of biochemistry \& cell biology. 2007;39(4):666-71.

24. Kirk TZ MM, Chua CC, Chua BH, Mayes MD. Myofibroblasts from scleroderma skin synthesize elevated levels of collagen and tissue inhibitor of metalloproteinase (TIMP-1) with two forms of TIMP-1. . The Journal of biological chemistry 1995;;270((7):):3423-8.

25. Piera-Velazquez S JS. Molecular mechanisms of endothelial to mesenchymal cell transition (EndoMT) in experimentally induced fibrotic diseases. . Fibrogenesis \& Tissue Repair. 2012;;5((Suppl 1):):S7-S.

26. Li Z, Jimenez SA. Protein kinase Cdelta and c-Abl kinase are required for transforming growth factor beta induction of endothelial-mesenchymal transition in vitro. Arthritis and rheumatism. 2011;63(8):2473-83.

27. Medici D, Potenta S, Kalluri R. Transforming growth factorbeta2 promotes Snail-mediated endothelial-mesenchymal transition through convergence of Smad-dependent and Smad-independent signalling. The Biochemical journal. 2011;437(3):515-20.

28. Piera-Velazquez S JS. Molecular mechanisms of endothelial to mesenchymal cell transition (EndoMT) in experimentally induced fibrotic diseases. Fibrogenesis Tissue Repair 2012;;5((Suppl 1):):S7.

29. van Meeteren LA, ten Dijke P. Regulation of endothelial cell plasticity by TGF-beta. Cell and tissue research. 2012;347(1):177-86.

30. Goumans MJ, Liu Z, ten Dijke P. TGF-beta signaling in vascular biology and dysfunction. Cell research. 2009;19(1):116-27.

31. Vandewalle C, Van Roy F, Berx G. The role of the ZEB family of transcription factors in development and disease. Cellular and molecular life sciences : CMLS. 2009;66(5):773-87.

32. Piera-Velazquez S MF, Jimenez SA. . Endothelial to Mesenchymal Transition (EndoMT) in the Pathogenesis of Human Fibrotic Diseases. Journal of clinical medicine. 2016;;5((4).).

33. Mustoe TA, Pierce GF, Thomason A, Gramates P, Sporn MB, Deuel TF. Accelerated healing of incisional wounds in rats induced by transforming growth factor-beta. Science (New York, NY). 1987;237(4820):1333-6.

34. Lin RY SK, Argenta PA, Meuli M, Lorenz HP, Adzick NS. . Exogenous transforming growth factor-beta amplifies its own expression and induces scar formation in a model of human fetal skin repair. Annals of surgery 1995;;222((2):):146-54.

35. Leask A AD. TGF-beta signaling and the fibrotic response. 
FASEB journal : official publication of the Federation of American Societies for Experimental Biology 2004;;18((7):):816-27.

36. Duncan MR FK, Abramson S, Williams S, Klapper H, Huang $\mathrm{X}$, et al. . Connective tissue growth factor mediates transforming growth factor beta-induced collagen synthesis: down-regulation by cAMP. . FASEB journal : official publication of the Federation of American Societies for Experimental Biology. 1999;;13((13):):1774-86.

37. Khan I, Agarwal P, Thangjam GS, Radhesh R, Rao SG, Kondaiah P. Role of TGF-beta and BMP7 in the pathogenesis of oral submucous fibrosis. Growth factors (Chur, Switzerland). 2011;29(4):119-27.

38. Haque MF MS, Khitab U, Harris M. . Oral submucous fibrosis patients have altered levels of cytokine production. Journal of oral pathology \& medicine : official publication of the International Association of Oral Pathologists and the American Academy of Oral Pathology. 2000;;29((3):):123-8.

39. Utsunomiya H TW, Oshiro K, Maruyama S, Suzuki M, IdaYonemochi $\mathrm{H}$, et al. . Extracellular matrix remodeling in oral submucous fibrosis: its stage-specific modes revealed by immunohistochemistry and in situ hybridization. . Journal of oral pathology \& medicine : official publication of the International Association of Oral Pathologists and the American Academy of Oral Pathology 2005;;34((8):):498507.

40. Ila Pant NK IK, Somanahalli Girish Rao, Published: . Paturu Kondaiah Role of Areca Nut Induced TGF- $\beta$ and EpithelialMesenchymal Interaction in the Pathogenesis of Oral Submucous Fibrosis. PLOS ONE. 5https://doi.org/10.1371/ journal.pone.0129252.June 24, 201 [

41. Maria S KV, Satelur K, Rajkumar K. . Evaluation of transforming growth factor betal gene in oral submucous fibrosis induced in Sprague-Dawley rats by injections of areca nut and pan masala (commercial areca nut product) extracts. Journal of cancer research and therapeutics 2016;;12((1):):379-85.

42. R. R. Oral submucous fibrosis: etiology, pathogenesis, and future research. Bulletin of the World Health Organization. 1994;;72((6):):985-96.

43. Pandiar D SP. Immunohistochemical expression of CD34 and basic fibroblast growth factor (bFGF) in oral submucous fibrosis. Journal of Oral and Maxillofacial Pathology. . 2014;;18((2))::155-61.

44. Sinor PN GP, Murti PR, Bhonsle RB, Daftary DK, Mehta FS, et al. A case-control study of oral submucous fibrosis with special reference to the etiologic role of areca nut. . Journal of oral pathology \& medicine : official publication of the International Association of Oral Pathologists and the American Academy of Oral Pathology 1990;;19((2):):94-8.

45. Jacob BJ, Straif K, Thomas G, Ramadas K, Mathew B, Zhang $\mathrm{ZF}$, et al. Betel quid without tobacco as a risk factor for oral precancers. Oral oncology. 2004;40(7):697-704.

46. Rajalalitha P VS. Molecular pathogenesis of oral submucous fibrosis--a collagen metabolic disorder. Journal of oral pathology \& medicine : official publication of the International Association of Oral Pathologists and the American Academy of Oral Pathology. 2005;;34((6):):3218.

47. Hsieh YP CH, Lin HY, Yang H, Chang JZ. . Epigallocatechin3-gallate inhibits transforming-growth-factor-beta1-induced collagen synthesis by suppressing early growth response- 1 in human buccal mucosal fibroblasts. Journal of the Formosan Medical Association = Taiwan yi zhi. 2017;;116((2):):10713.

48. Yang SF, Hsieh YS, Tsai CH, Chou MY, Chang YC. The upregulation of type I plasminogen activator inhibitor in oral submucous fibrosis. Oral oncology. 2003;39(4):367-72.

49. Prime SS PM, Davies M, Paterson IC. . TGF-beta signal transduction in oro-facial health and non-malignant disease (part I). Critical reviews in oral biology and medicine : an official publication of the American Association of Oral Biologists. 2004;;15((6):):324-36.

50. KR. C. TGF-beta-induced fibrosis and SMAD signaling: oligo decoys as natural therapeutics for inhibition of tissue fibrosis and scarring. Wound repair and regeneration : official publication of the Wound Healing Society [and] the European Tissue Repair Society. . 2007;;15 (Supp1 1:):S54-60.

51. Feres-Filho EJ CY, Han X, Takala TE, Trackman PC. . Pre- and post-translational regulation of lysyl oxidase by transforming growth factor-beta 1 in osteoblastic MC3T3-E1 cells. . The Journal of biological chemistry 1995;;270((51):):30797-803.

52. Hong HH UM, Duan C, Sheff MC, Trackman PC. Regulation of lysyl oxidase, collagen, and connective tissue growth factor by TGF-betal and detection in human gingiva. Laboratory investigation; . a journal of technical methods and pathology. 1999;;79((12):):1655-67.

53. Moutasim KA JV, Sapienza K, Marsh D, Weinreb PH, Violette SM, et al. . Betel-derived alkaloid up-regulates keratinocyte alphavbeta 6 integrin expression and promotes oral submucous fibrosis. The Journal of pathology 2011;;223((3):):366-77.

54. Prabhu RV, Prabhu V, Chatra L, Shenai P, Suvarna N, Dandekeri S. Areca nut and its role in oral submucous fibrosis. Journal of clinical and experimental dentistry. 2014;6(5):e569-75.

55. Ahmad MS AS, Ali AS, Chaubey KK. . Epidemiological and etiological study of oral submucous fibrosis among gutkha chewers of Patna, Bihar, India. . Journal of the Indian Society of Pedodontics and Preventive Dentistry. 2006;;24((2):):84-9.

56. Murti PR BR, Pindborg JJ, Daftary DK, Gupta PC, Mehta FS. . Malignant transformation rate in oral submucous fibrosis over a 17 -year period. Community dentistry and oral epidemiology. . 1985;;13((6):):340-1.

57. Angadi PV, Rao S. Management of oral submucous fibrosis: an overview. Oral and maxillofacial surgery. 2010;14(3):133-42.

58. Krishnamoorthy B, Khan M. Management of oral submucous fibrosis by two different drug regimens: A comparative study. Dental research journal. 2013;10(4):527-32.

59. Eickelberg O PA, Koehler E, Bihl M, Tamm M, Hildebrand P, et al. . Molecular mechanisms of TGF-(beta) antagonism by interferon (gamma) and cyclosporine A in lung fibroblasts. FASEB journal : official publication of the Federation of American Societies for Experimental Biology. $2001 ; ; 15((3):): 797-806$.

60. Nishijima N, Seike M, Soeno C, Chiba M, Miyanaga A, Noro $\mathrm{R}$, et al. miR-200/ZEB axis regulates sensitivity to nintedanib in non-small cell lung cancer cells. International journal of oncology. 2016;48(3):937-44.

61. Li Z LX, Wang B, Nie Y, Wen J, Wang Q, et al. . Pirfenidone suppresses MAPK signalling pathway to reverse epithelialmesenchymal transition and renal fibrosis. . Nephrology (Carlton, Vic) 2017;;22((8):):589-97.

62. Yoithapprabhunath TR MT, Dineshshankar J, Anusushanth A, Sindhuja P, Sitra G. . Pathogenesis and therapeutic intervention of oral submucous fibrosis. . Journal of Pharmacy \& Bioallied Sciences. 2013;;5((Suppl 1):):S85-S8. 63. Chole RH, Gondivkar SM, Gadbail AR, Balsaraf S, 
Chaudhary S, Dhore SV, et al. Review of drug treatment of oral submucous fibrosis. Oral oncology. 2012;48(5):393-8.

64.Gadekar SM. 5-Methyl-1-phenyl-2-(1H)-pyridone compositions and methods of use. 1976. Aug $10 \mathrm{iUp}$, 974,281.

65. Margolin SB. Composition and method for reparation and prevention of fibrotic lesions. 1994. May 10 iUp, 310,562.

66. Lee BS, Margolin SB, Nowak RA. Pirfenidone: a novel pharmacological agent that inhibits leiomyoma cell proliferation and collagen production. The Journal of clinical endocrinology and metabolism. 1998;83(1):219-23.

67. Zhang S, Shiels IA, Ambler JS, Taylor SM. Pirfenidone reduces fibronectin synthesis by cultured human retinal pigment epithelial cells. Australian and New Zealand journal of ophthalmology. 1998;26 Suppl 1:S74-6.

68. Iyer SN, Gurujeyalakshmi G, Giri SN. Effects of pirfenidone on procollagen gene expression at the transcriptional level in bleomycin hamster model of lung fibrosis. The Journal of pharmacology and experimental therapeutics. 1999;289(1):211-8.

69. Tada S NM, Enjoji M, Sugimoto R, Iwamoto H, Kato M, et al. . Pirfenidone inhibits dimethylnitrosamine-induced hepatic fibrosis in rats. . Clinical and experimental pharmacology \& physiology $2001 ; ; 28((7):): 522-7$.

70. Nguyen DT DC, Wilson E, Marcus GM, Olgin JE. . Pirfenidone mitigates left ventricular fibrosis and dysfunction after myocardial infarction and reduces arrhythmias. Heart rhythm 2010;;7((10):):1438-45.

71. Gan Y, Herzog EL, Gomer RH. Pirfenidone treatment of idiopathic pulmonary fibrosis. Therapeutics and clinical risk management. 2011;7:39-47.

72. Garcia L, Hernandez I, Sandoval A, Salazar A, Garcia J, Vera J, et al. Pirfenidone effectively reverses experimental liver fibrosis. Journal of hepatology. 2002;37(6):797-805.

73. Yu CC, Tsai CH, Hsu HI, Chang YC. Elevation of S100A4 expression in buccal mucosal fibroblasts by arecoline: involvement in the pathogenesis of oral submucous fibrosis. PloS one. 2013;8(1):e55122.

74. Nakazato H OH, Yamane S, Tsuruta Y, Suzuki R. . A novel anti-fibrotic agent pirfenidone suppresses tumor necrosis factor-alpha at the translational level. . European journal of pharmacology. 2002;;446((1-3):):177-85.

75. Kaur J JR. Proinflammatory cytokine levels in oral lichen planus, oral leukoplakia, and oral submucous fibrosis. Journal of the Korean Association of Oral and Maxillofacial Surgeons 2015;;41((4):):171-5.

76. Bishen KA RR, Satyamoorthy K. . The role of basic fibroblast growth factor in oral submucous fibrosis pathogenesis. Journal of oral pathology \& medicine : official publication of the International Association of Oral Pathologists and the American Academy of Oral Pathology. 2008;;37((7):):40211.

77. Tsai CH LS, Chang YC. . Hypoxic regulation of plasminogen activator inhibitor-1 expression in human buccal mucosa fibroblasts stimulated with arecoline. Journal of oral pathology \& medicine : official publication of the International Association of Oral Pathologists and the American Academy of Oral Pathology. 2015;;44((9):):66973.

78. Hilberg F, Roth GJ, Krssak M, Kautschitsch S, Sommergruber W, Tontsch-Grunt U, et al. BIBF 1120: triple angiokinase inhibitor with sustained receptor blockade and good antitumor efficacy. Cancer research. 2008;68(12):4774-82.

79. Hostettler KE ZJ, Papakonstantinou E, Karakiulakis G, Tamm M, Seidel P, et al. . Anti-fibrotic effects of nintedanib in lung fibroblasts derived from patients with idiopathic pulmonary fibrosis. Respiratory research. . 2014;;15::157.

80. Wollin L, Maillet I, Quesniaux V, Holweg A, Ryffel B. Antifibrotic and anti-inflammatory activity of the tyrosine kinase inhibitor nintedanib in experimental models of lung fibrosis. The Journal of pharmacology and experimental therapeutics. 2014;349(2):209-20.

81. Rangarajan S, Kurundkar A, Kurundkar D, Bernard K, Sanders YY, Ding Q, et al. Novel Mechanisms for the Antifibrotic Action of Nintedanib. American journal of respiratory cell and molecular biology. 2016;54(1):51-9.

82. Seema Nayak MMG AM, Vikram Bhatia, Saumya Chandra, Sandeep Kumar, S. P. Agarwal. Published: . Fibroblast Growth Factor (FGF-2) and Its Receptors FGFR-2 and FGFR-3 May Be Putative Biomarkers of Malignant Transformation of Potentially Malignant Oral Lesions into Oral Squamous Cell Carcinoma. PLOS ONE. https://doi. org/10.1371/journal.pone.0138801.October 14, 2015 [

83. Hajari Case A, Johnson P. Clinical use of nintedanib in patients with idiopathic pulmonary fibrosis. BMJ open respiratory research. 2017;4(1):e000192.

84. Lancaster LH dAJ, Zibrak JD, Padilla ML, Albera C, Nathan $\mathrm{SD}$, et al. . Pirfenidone safety and adverse event management in idiopathic pulmonary fibrosis. . European Respiratory Review. 2017;;26((146).).

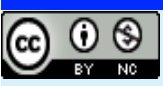

This work is licensed under a Creative Commons AttributionNon Commercial 4.0 International License. 